involving methotrexate with sulfasalazine or hydroxychloroquine, or sulfasalazine plus hydroxychloroquine were allowed. Clinic visits occurred at baseline and weeks 1, 2, 4, 8, and 12 . Study related observations consisted of efficacy assessments, physical examination, laboratory assessments, adverse events (noninfectious adverse events and infectious episodes), concomitant medications, PEG sTNF-RI antibodies, and autoantibodies.

Results A total of 195 subjects were randomised and 194 subjects received $>=1$ dose of study drug. Efficacy: Subjects in the $800 \mu \mathrm{g} / \mathrm{kg}$ PEG sTNF-RI dose group had an ACR20 response rate of $50 \%$ which was significantly different $(\mathrm{p}=0.005)$ from the placebo group (26\%). TheACR20 response rate for the 400 $\mu \mathrm{g} / \mathrm{kg}$ group was $33 \%$ (NS vs. placebo). An increasing ACR20 response rate with increasing PEG sTNF-RI dose was detected at week 12 ( $\mathrm{p}=0.017)$. Treatment with $800 \mu \mathrm{g} / \mathrm{kg}$ PEG sTNF-RI resulted in statistically significant improvements in all individual ACR components except for swollen joint counts and CRP. Safety: No deaths or malignancies were reported. Two subjects experienced serious events; neither event was judged to be related to study drug or resulted in withdrawal from the study. The incidence of infectious episodes was slightly higher in subjects receiving PEG sTNF-RI (27\%) compared with subjects receiving placebo (21\%). Only the incidence of injection site reactions appeared to be treatmentÓrelated; (20\% PEG sTNFRI, $10 \%$ placebo). Noninfectious adverse events that occurred more frequently in PEG sTNF-RI subjects compared with placebo included diarrhoea ( $8 \%$ vs. $3 \%$ ), dizziness (6\% vs. $3 \%)$, and nausea (6\% vs. $3 \%)$. No PEG sTNF-RI treatmentÓrelated effects on laboratory variables, vital signs, or antibodies were evident.

Conclusion Weekly dosing with PEG sTNF-RI (400- or $800-\mu \mathrm{g}$ / $\mathrm{kg}$ ) for 12 weeks demonstrated a beneficial treatment effect in improving the signs and symptoms of subjects with RA. Treatment with PEG sTNF-RI appeared to be safe and well-tolerated. The type and incidence of adverse events was similar to those observed in clinical trials with other TNF- $\alpha$ inhibitors. Further patient exposure will be required to fully characterise the adverse event profile of PEG sTNF-RI in subjects with rheumatoid arthritis. Future studies will evaluate higher and more frequent dosing.

\section{FRI0060 SUCCESSFUL TREATMENT OF ACTIVE RHEUMATOID ARTHRITIS WITH CHIMERIC MONOCLONAL ANTIBODY TO TUMOUR NECROSIS FACTOR (INFLIXIMAB): AN OPEN STUDY}

KA Boki, VA Vassiliou, G Linardaki, HM Moutsopoulos. Department of Pathophysiology, National University of Athens School of Medicine, Athens, Greece

\subsection{6/annrheumdis-2001.1189}

Background Infliximab is a chimeric anti-tumour necrosis factor $\alpha($ anti-TNF $\alpha)$ monoclonal IgG1 antibody, neutralising the soluble cytokine and blocking the membrane bound cytokine that is used successfully for the treatment of active rheumatoid arthritis (RA) not controlled with other disease modified anti-rheumatic drugs (DMARDs).

Objectives The clinical evaluation of infliximab in the treatment of active RA.

Methods Twenty-four (24) patients (pts) with active RA (20 women and 4 men), mean age $46.4 \pm 10.17$ (years), and mean disease duration $9.9 \pm 7.77$ (years) received infliximab in a combination with Methotrexate $10 \mathrm{mg} /$ week and Prednizolone 7.5-
$10 \mathrm{mg} /$ day in an open unrandomized trial. Thirteen (13) pts completed three months therapy with infliximab and 11 pts six months. Infliximab was given at a dose of $3 \mathrm{mg} / \mathrm{kg}$ of body weight at week 0,2 and 6 of treatment protocol and then every 8 weeks. All these pts had received combination therapy with DMARDs for more than three months, before enrolling in the study, without sufficient improvement. Active RA was defined by 10 or more swollen joints $(10.9 \pm 4.7), 12$ or more tender joints $(13.4 \pm 5.11)$, ESR $>28 \mathrm{~mm}(48.0 \pm 19.23 \mathrm{~mm})$ and C-reactive protein $>5.0 \mathrm{mg} / \mathrm{dl}(37.4 \pm 12.69 \mathrm{mg} / \mathrm{dl})$. A statistical analysis was done after the third and sixth month of treatment.

Results At three months, the number of swollen joints was reduced to $3.3 \pm 2.73(\mathrm{p}<0.001)$ and the number of tender joints was, also, reduced to $4.1 \pm 3.17$ ( $\mathrm{p}<0.001$ ), ESR was $29.0 \pm 20.5 \mathrm{~mm}(\mathrm{p}<0.001)$ and CRP $18.6 \pm 13.05 \mathrm{mg} / \mathrm{dl}(\mathrm{p}$ $<0.001$ ). At six months, statistically significant difference was not observed in any of the parameters of disease activity: swollen joints were $2.8 \pm 2.01$ (NS), tender joints $5.6 \pm 4.3$ (NS), ESR $24.6 \pm 19.3 \mathrm{~mm}$ (NS) and CRP $15.4 \pm 12.3 \mathrm{mg} / \mathrm{dl}(\mathrm{NS})$. Four female pts were excluded from the study and the statistical analysis: one patient because of unsufficient respond, another patient because of allergic reaction during the 5 th infusion, and 2 pts because of uncontrolled urinary track infection after the $3 \mathrm{rd}$ infusion. All the pts declare dizziness, light headache, nausea, 2 pts reported abdominal pain after the first infusion and 2 pts increased hairing loss. One patient with alopecia areata universalis reported hair improvement but this result was only for a small period of time.

Conclusion The initiation of infliximab therapy in patients with active RA resulted in a fast and significant improvement of peripheral articular manifestations and quality of life. Even though major adverse events were not reported, the clinicians should be aware of this possibility.

\section{FRI0061 ANAKINRA ARRESTS JOINT DESTRUCTION IN PATIENTS WITH RA AND ESTABLISHED EROSIONS}

${ }^{1}$ B Bresnihan, ${ }^{2} \mathrm{D}$ McCabe, ${ }^{3}$ I Watt, ${ }^{4} \mathrm{H}$ Genant, ${ }^{2} \mathrm{~S}$ Robbins, ${ }^{2} \mathrm{RD}$ Newmark. ${ }^{1}$ Department of Rheumatology, St. Vincent's University Hospital, Dublin 4, Ireland; ${ }^{2}$ Clinical Development, Amgen Inc., Thousand Oaks, USA; ${ }^{3}$ Department of Radiology, University of Bristol, Bristol, UK; ${ }^{4}$ Department of Radiology, University of San Francisco, San Francisco, USA

10.1136/annrheumdis-2001.1190

Background Patients with active RA and manifest erosive disease (at least 1 joint erosion) are likely to develop further joint damage.

Objectives The aim of this study was to evaluate the effect of anakinra on progressive joint damage in patients with erosive disease.

Methods Serial radiographs were obtained during a 24 week randomised placebo controlled study of $30 \mathrm{mg}, 75 \mathrm{mg}$ or 150 $\mathrm{mg}$ anakinra daily. Joint damage was quantified using both the Larsen and modified Sharp methods (Genant A\&R, 41:1583, 98). Patients with at least 1 erosion at baseline were selected for study.

Results Approximately $75 \%$ of the 472 patients enrolled in the study had erosive disease (range $71-78 \%$ for each treatment group). The mean changes from baseline were highly significant for each anakinra dose group, when compared with placebo for reduction in the rate of joint destruction. The 75 and $150 \mathrm{mg}$ dose groups arrested joint destruction (no radiographic progression) in a higher proportion of patients compared with placebo. A dose response was observed with regard to both the mean 
change from baseline of the modified Sharp scores and proportion of patients in whom joint destruction was arrested after 24 weeks of treatment.

\begin{tabular}{lllll}
\multicolumn{4}{l}{ Abstract FRI0061 Table 1} \\
\hline & Placebo & $\mathbf{3 0} \mathbf{~ m g}$ & $\mathbf{7 5} \mathbf{m g}$ & $150 \mathrm{mg}$ \\
\hline Mod. Sharp Score: mean & 4.33 & $2.36 \mathrm{p}=$ & $2.25 \mathrm{p}=$ & $1.72 \mathrm{p}=$ \\
change & & 0.005 & 0.003 & 0.0004 \\
Mod. Sharp Score:\% pt w/no & $16.7 \%$ & $31 \% \mathrm{p}=$ & $24 \% \mathrm{p}=$ & $31 \% \mathrm{p}=$ \\
change & & 0.026 & 0.234 & 0.022 \\
\hline
\end{tabular}

Conclusion In patients with erosive disease, the rate of deterioration was significantly less in those who received anakinra. Significantly more patients with erosive RA who received anakinra for 24 weeks demonstrated an arrest of progressive joint damage. Moreover, an increasing benefit was associated with increasing dosages.

\section{FRI0062 EFFECTS OF METHOTREXATE AND LONG TERM LOW PREDNISONE DOSES ON BONE MINERAL DENSITY IN PATIENTS WITH EARLY SEVERE RHEUMATOID ARTHRITIS}

Cl Chirieac, E Rezus, B Florica, D Stratan, R Chiriac. Rheumatology, Rehabilitation Hospital - University of Medicine and Pharmacy, lasi, Romania

\subsection{6/annrheumdis-2001.1191}

Background Patients suffering from rheumatoid arthritia (RA) may feature significant loss of bone mineral density (BMD). early aggressive treatment and sometimes low corticosteroids doses are required; however, long term effects on bone are not extensively characterised.

Objectives To assess the effects of $10 \mathrm{mg}$ prednisone daily +7.5 mg methotrexate (MTX) on BMD in patients with early active and severe RA.

Methods 32 patients with active RA, with a disease duration less than 2 years, without prior treatment with any disease modifying antirheumatic drugs were randomised to receive either MTX and prednisone or sulphasalazine alone. Osteoporosis treatment was not permitted. Disease activity and BMD were monitored at baseline, 6, 12 and 24 months; BMD was determined by quantitative ultrasound at the calcis bone and was appreciated as broadband ultrasound attenuation (BUA) and quantitative ultrasound index (QUI). BMD loss was calculated in \% of baseline. Subgroup analysis (high and low disease activity) was performed upon ESR and CRP values.

Results After 6 and 12 months of treatment mean\% BUA has decreased significantly $(p<0.05)$ compared to baseline in both study groups, but greater in patients with high disease activity; after 24 months BMD has fallen significantly more in the combination group in patients with severe RA (- 3.5\%) compared to monotherapy group in patients with mild disease $(+0.07 \%, \mathrm{p}<$ $0.05)$. Change in BMD correlates more closely with measure of inflammation than with administration of prednosone and MTX.

Conclusion High disease activity is closely associated with bone loss in early active severe RA compared to bone loss due to aggressive therapy including MTX and low doses prednisone.
FRI0063 ANAKINRA REDUCES THE RATE OF JOINT DESTRUCTION AFTER 1 YEAR OF TREATMENT IN A RANDOMISED CONTROLLED COHORT OF PATIENTS WITH RHEUMATOID ARTHRITIS

${ }^{1} \mathrm{~B}$ Bresnihan, ${ }^{2} \mathrm{RD}$ Newmark, ${ }^{2} \mathrm{~S}$ Robbins, ${ }^{2} \mathrm{D}$ McCabe, ${ }^{3} \mathrm{HK}$ Genant. ${ }^{1}$ Department of Rheumatology, St. Vincent's University Hospital, Dublin, Ireland; ${ }^{2}$ Clinical Development, Amgen Inc., Thousand Oaks, USA; ${ }^{3}$ Department of Radiology, University of San Francisco, San Francisco, USA

\subsection{6/annrheumdis-2001.1192}

\section{Background}

Objectives To assess the effect of ankinra on progressive joint damage in patients with rheumatoid arthritis after 12 months of treatment.

Methods 472 patients were randomised to a 24 week study. On completing the 24 week, placebo-controlled, randomised clinical trial, patients receiving anakinra 30,75 or $150 \mathrm{mg}$ daily continued blinded treatment for a further 24 weeks. Patients originally randomised to placebo were re-randomised to blinded treatment with one of the 3 anakinra doses for an additional 24 weeks resulting in a blinded cohort of patients $(\mathrm{N}=309)$ followed for up to 1 year by radiographic assessments, using a modified Sharp method (Genant A\&R, 41:1583, 98).

Results Treatment with 75 or $150 \mathrm{mg}$ anakinra was significantly superior in terms of reducing joint destruction after 1 year, when compared to the group of patients originally randomised to placebo. This analysis demonstrated a dose proportional relationship with increasing doses of anakinra providing superior reduction of joint destruction when measured by a modified Sharp score.

Abstract FRI0063 Table 1 p-values for pairwise comparisons vs placebo are the result of an analysis using a repeated measures mixed model.

\begin{tabular}{lllll}
\hline & $\begin{array}{l}\text { Placebo } \mathrm{n}= \\
59\end{array}$ & $\begin{array}{l}30 \mathrm{mg} \mathrm{n} \\
=66\end{array}$ & $\begin{array}{l}75 \mathrm{mg} \mathrm{n} \\
=64\end{array}$ & $\begin{array}{l}150 \mathrm{mg} \mathrm{n} \\
=48\end{array}$ \\
\hline $\begin{array}{l}\text { Mean change in mod. Sharp } \\
\text { score after 1 year }\end{array}$ & 3.81 & $\begin{array}{l}2.43 \mathrm{p}= \\
0.099\end{array}$ & $\begin{array}{l}1.91 \mathrm{p}= \\
0.025\end{array}$ & $\begin{array}{l}1.90 \mathrm{p}= \\
0.025\end{array}$ \\
\hline
\end{tabular}

Conclusion Anakinra provides a statistically significant reduction in joint destruction, compared with patients originally randomised to placebo after 1 year of treatment. The reduction in joint destruction was dose proportional.

\section{FRI0064 PENTOXIFYLLINE THERAPY FOR REMISSION MAINTENANCE IN RHEUMATOID VASCULITIS}

'LO Damian, 'S Rednic, ${ }^{2} \mathrm{~A}$ Cristea, ${ }^{1} \mathrm{H}$ Bolosiu. 'Rheumatology; ${ }^{2}$ Immunology, University of Medicine and Pharmacy Cluj-Napoca, Cluj-Napoca, Romania

\subsection{6/annrheumdis-2001.1193}

Background Pentoxifylline (PTX), a phosphodiesterase inhibitor, is a vasodilator and antiplatelet drug credited with TNF $\alpha$ transcription inhibition as well. PTX was successfully used in refractory cases of rheumatoid arthritis and in some vasculitides, mainly cutaneous.

Objectives The study aim was to evaluate the efficacy of PTX given as monotherapy after induction of remission in systemic rheumatoid vasculitis (RV). 